\title{
Detection of hypertension and its relation to other cardiovascular risk factors in adolescents who request a medical fitness certificate for school
}

\author{
Micaela Amor, M.D. ${ }^{a}$, Luciana Pronsky, M.D. ${ }^{a}$, Carla Irazabal, M.D. ${ }^{a}$, Sofía Ortiz de Latierro, M.D. ${ }^{a}$, \\ María B. Tapia, M.D. ${ }^{a}$ and Eugenia Sarcona, M.D. ${ }^{a}$
}

\begin{abstract}
Arterial hypertension (HTN) may begin in childhood and is related to other risk factors, such as obesity and a sedentary lifestyle.

In this study, the prevalence of HTN was estimated and the factors associated with it were assessed in adolescents aged 1519 years who attended the Center for Health and Community Action no. 12 to request their medical fitness certificate for school. The following data were collected: age, sex, family history of HTN, current smoking, physical activity, weight, height, waist circumference, and blood pressure.

A total of 289 adolescents were assessed; their mean age was 16.6 years. Among them, $48.6 \%$ were males; $6.6 \%$ had HTN; $10.9 \%$ were obese; and $13.4 \%$ had a larger waist circumference. The presence of HTN was significantly associated with obesity and a larger waist circumference, but no significant association was observed with the other studied outcome measures. Key words: adolescent, arterial hypertension, sedentary lifestyle, obesity, fitness.

http: / / dx.doi.org/10.5546/ aap.2019.eng.344
\end{abstract}

To cite: Amor M, Pronsky L, Irazabal C, Ortiz de Latierro S, et al. Detection of hypertension and its relation to other cardiovascular risk factors in adolescents who request a medical fitness certificate for school. Arch Argent Pediatr 2019;117(5):344-347.

a. Center for Health and Community Action no. 12, Programmatic Area of Hospital "Ignacio Pirovano," Autonomous City of Buenos Aires.

E-mail address:

Eugenia Sarcona, M.D: ugesarcona@hotmail.com

Funding: None.

Conflict of interest: None.

Received: 10-22-2018

Accepted: 4-16-2019

\section{INTRODUCTION}

Cardiovascular disease is still the most common cause of disability and death and the second leading cause of chronic kidney failure in adults, both in Argentina and worldwide. ${ }^{1,2}$ In many cases, this may be prevented, and an adequate management of blood pressure (BP) and other risk factors (RFs) since childhood reduces the incidence of cardiovascular disease in adulthood. ${ }^{3}$

The pandemic of obesity in children and adolescents, together with the risk for early ventricular hypertrophy and atherosclerosis, makes it relevant to track cardiovascular RFs since childhood to reduce long-term health risks. Essential HTN is the leading cause of HTN in adolescents, with multiple associated RFs; of these, obesity is the most prevalent one. ${ }^{4}$

There is little information about the prevalence of HTN in healthy adolescents worldwide and in our setting in particular, with values that range from $2 \%$ to $8 \%$ in the population younger than 18 years., ${ }^{5,6}$

Considering that the level of $\mathrm{BP}$ in adolescence is the main RF for HTN in adulthood, ${ }^{7}$ it is interesting to establish the prevalence of HTN in this age group and its relation to other cardiovascular RFs to implement early preventive and health promotion actions.

\section{OBJECTIVE}

To estimate the prevalence of HTN and assess the factors associated with it in adolescents who request a medical fitness certificate (MFC) for school.

\section{MATERIALS AND METHODS}

Design: Cross-sectional, analytical study.

Inclusion criteria: Adolescents aged 1519 years who attended the Center for Health and Community Action (Centro de Salud y Acción Comunitaria, CeSAC) no. 12, which depends on Hospital "Ignacio Pirovano" in the Autonomous City of Buenos Aires, to request a 
MFC between May and October 2017 and who agreed to participate in the study.

Exclusion criteria: Patients with HTN receiving medication, diagnosed secondary HTN, diabetes, history of kidney or cardiovascular disease, and a history of juvenile rheumatic disease.

\section{Outcome measures \\ Blood pressure}

- HTN: average systolic and/or diastolic BP $\geq 95^{\text {th }}$ percentile.

- High blood pressure: average systolic and / or diastolic $\mathrm{BP} \geq 90^{\text {th }}$ and $<95^{\text {th }}$ percentile.

- Normal blood pressure: average systolic and/ or diastolic $\mathrm{BP}<90^{\text {th }}$ percentile.

BP measurement: BP was measured with the participant in sitting position, with the back against the backrest and the dominant arm at the level of the heart, after 30 minutes of not smoking or doing physical activity (PA). The average value was established among 3 measurements made every 2 minutes using a semi-automatic sphygmomanometer (Omron HEM-741 CINT).

Body mass index (BMI): It was estimated based on the weight $(\mathrm{kg}) /$ height $\left(\mathrm{m}^{2}\right)$ formula. A BMI percentile $>85$ was used to define overweight and a BMI percentile $>97$, to refer to obesity. ${ }^{8}$

Waist circumference: The circumference was measured at the upper edge of the iliac crest using a non-extensible tape measure (Calibres Argentinos). The participant was standing, with the waist uncovered, both arms relaxed on the sides and breathing calmly. Waist circumference was considered larger if it was $>90^{\text {th }}$ percentile. ${ }^{8}$

PA: It was defined as the number of daily minutes spent doing PA. All minutes spent every day of the week doing PA were added and divided by 7 to establish the average daily minutes. Participants were considered to have a sedentary lifestyle if they did less than 60 minutes of PA every day. ${ }^{9}$

Family history of HTN: Adolescents who referred that their father and/or mother had HTN were considered to have a positive family history.

Smoking: Current smoking was considered positive.

Sex: Biological sex.

Age: Years and months old.

\section{Statistical analysis}

Adolescents were assessed by sex and height using the standard charts proposed by the Sociedad Argentina de Pediatría and then they were assigned by age and height percentile to the BP charts proposed by the American Academy of Pediatrics. ${ }^{10,11}$

Outcomes were described using absolute numbers and percentages or mean and standard deviation, as applicable. For the univariate and multivariate analysis, the $\chi^{2}$ test or Fisher's exact test and logistic regression were used. A $p$ value $<0.05$ was considered statistically significant, and the $95 \%$ confidence interval (CI) was estimated. The Statistix version 8.0 and VCCstat v.Beta 2.11 statistical software programs were used.

\section{Ethical considerations}

This study was approved by the Research Ethics Committee of Hospital "Ignacio Pirovano" and, in all cases, the participants' written informed consent was obtained.

All adolescents and their family members who were observed to have a RF were given advice on it and were asked to return for a visit to confirm diagnosis and receive follow-up.

\section{RESULTS}

A total of 289 adolescents aged 15-19 years were assessed. One patient was excluded because she was receiving antihypertensive drugs. All other patients who attended the CeSAC no. 12 to request a MFC agreed to participate in the study and were eligible.

Mean age: 16.6 years; $134(46.4 \%)$ were males; $19(6.6 \%)$ had HTN; $66(22.8 \%)$, high BP; 33 (11.4\%), obesity; 41 (14.2\%), overweight; $42(14.5 \%)$, larger waist circumference (LWC); $63(21.8 \%)$, family history of HTN; $33(11.4 \%)$, smoking; $232(80.3 \%)$, sedentary lifestyle (Table 1).

The univariate analysis found a significant association between HTN values and male sex $(p<0.001$, odds ratio [OR]: $6.9,95 \%$ CI: 2-23.9), obesity and overweight ( $p<0.001$, OR: $5.7,95 \%$ CI: 2.2-15.2), and LWC ( $p<0.001$, OR: 8.3, $95 \%$ CI: 3.1-21.9) (Table 2).

In the multivariate analysis adjusted for sex, obesity -estimated as per BMI and LWCcontinued showing a significant and independent relation to the presence of HTN (LWC: $p<0.001$, OR: $10.2,95 \%$ CI: 3.6-28.8; obesity and overweight: $p<0.001$, OR: 7.3, $95 \%$ CI: 2.6-20.0; obesity: $p<0.001$, OR: 11.8, $95 \%$ CI: 4.0-34.7) (Table 3).

\section{DISCUSSION}

In the studied adolescents, the prevalence of HTN was observed to be $6.6 \%$ and mainly 
associated with obesity and overweight, which had a prevalence of $11.4 \%$ and $14.2 \%$, respectively.

The study of cardiovascular risk factors in adolescents (ERICA) ${ }^{5}$ suggested that cardiovascular disease started early in life and that the risk for it was determined by the synergistic effect of cardiovascular RFs over time. The frequent association among obesity, sedentary lifestyle, dyslipidemia, and diabetes increased the atherogenic power of HTN.

In another study, ${ }^{12}$ overweight and obese adolescents had more body fat and a higher BP than normal weight adolescents. Also, a

TABLE 1. General characteristics. $N=289$

\begin{tabular}{|c|c|c|c|}
\hline & & $\%(\mathrm{n})$ & $95 \% \mathrm{CI}$ \\
\hline \multirow[t]{6}{*}{ Age (years) (mean $\pm \mathrm{SD})$} & & $16.6 \pm 1.29$ & \\
\hline & 15 & $22.5(65)$ & \\
\hline & 16 & $28(81)$ & \\
\hline & 17 & $23.9(69)$ & \\
\hline & 18 & $13.8(40)$ & \\
\hline & 19 & $11.8(34)$ & \\
\hline \multirow[t]{2}{*}{ Sex } & Girls & $53.6(155)$ & \\
\hline & Boys & $46.4(134)$ & \\
\hline Family history of HTN & & $21.8(63)$ & 17.3-27.1 \\
\hline Current smoking & & $11.4(33)$ & $8.1-15.8$ \\
\hline Sedentary lifestyle & & $80.3(232)$ & $75.1-84.6$ \\
\hline Larger waist circumference & & $14.5(42)$ & $10.8-19.2$ \\
\hline \multirow[t]{2}{*}{ Nutritional status } & Overweight & $14.2(41)$ & $10.5-18.9$ \\
\hline & Obesity & $11.4(33)$ & 8.1-15.8 \\
\hline High blood pressure & & $22.8(66)$ & $18.2-28.2$ \\
\hline HTN & & $6.6(19)$ & 4.1-10.2 \\
\hline
\end{tabular}

CI: confidence interval; SD: standard deviation; HTN: hypertension.

TABLE 2. Univariate analysis. $N=289$

\begin{tabular}{|c|c|c|c|c|c|c|}
\hline & All & HTN, n (\%) & No HTN, n (\%) & $p$ & OR & $95 \% \mathrm{CI}$ \\
\hline Boys (b) & $134(46.4)$ & $16(5.5)$ & $118(40.8)$ & $<0.001$ & 6.9 & $2-23.9$ \\
\hline Sedentary lifestyle (b) & $232(80.3)$ & $14(4.8)$ & $218(75.4)$ & 0.46 & 0.7 & $0.2-1.9$ \\
\hline Family history (a) & $63(21.8)$ & $5(1.7)$ & $58(20.1)$ & 0.62 & 1.3 & $0.4-3.8$ \\
\hline Smokers (a) & $33(11.4)$ & $2(0.7)$ & $31(10.7)$ & 0.9 & 0.9 & $0.2-4.1$ \\
\hline Larger waist circumference (b) & $42(14.5)$ & $10(3.5)$ & $32(11.1)$ & $<0.001$ & 8.3 & $3.1-21.9$ \\
\hline Obesity and overweight (b) & $74(28.7)$ & $12(4.1)$ & $62(21.4)$ & $<0.001$ & 5.7 & $2.2-15.2$ \\
\hline Obesity (b) & $33(11.4)$ & $9(3.1)$ & $24(8.3)$ & $<0.001$ & 9.2 & 3.4-24.9 \\
\hline
\end{tabular}

CI: confidence interval; OR: odds ratio; HTN: hypertension.

(a) Fisher's exact test, (b) $\chi^{2}$ test, $\mathrm{p}=0.05$.

TABLE 3. Multivariate analysis. $N=289$

\begin{tabular}{lccccc}
\hline & Coefficient & Standard error & $\boldsymbol{p}$ & OR & 95 $\%$ CI \\
\hline Sex & 2.16 & 0.66 & 0.001 & $2.7-31$ \\
Obesity and overweight & 1.98 & 0.51 & $<0.001$ & 7.3 \\
Obesity & 2.46 & 0.55 & $<0.001$ & 11.8 \\
Larger waist circumference & 2.32 & 0.53 & $<0.001$ & $4.0-34.7$ & 10.2 \\
\hline
\end{tabular}

OR: odds ratio; CI: confidence interval.

Logistic regression; the presence of obesity and overweight, obesity, and larger waist circumference was adjusted for male sex in relation to HTN. $\mathrm{p}=0.05$. 
relationship was observed between nutritional status and BP in both male and female adolescents.

The increase of obesity, estimated by both BMI and waist circumference, showed a close relation to high BP values in our study and in similar studies carried out in different parts of Argentina and at an earlier age, before the onset of adolescence. ${ }^{13-15}$

No significant relation was observed between high BP values and RFs, such as family history, sedentary lifestyle, and smoking. This is believed to be explained by the small sample size, the main limitation of this study. It is also worth noting the high percentage of sedentary lifestyle $(80.3 \%)$. In part, it is considered to be due to the parameter selected to estimate it (60 minutes of PA every day) and the fact that the studied adolescents were not allowed to do PA at school until they obtained the MFC, and this was the time when the study was conducted. Thus, measured PA corresponded to exercise done outside school, which would probably increase the prevalence of sedentary lifestyle.

On the other side, in this study, BP was measured in the dominant arm and not always in the right arm, which may lead to underdiagnosing HTN in left-handed patients with coarctation of the aorta. Such underestimation is expected to be minimized given the study participants' age, the low prevalence of coarctation of the aorta, and the fact that most of the population was right-handed.

It is worth noting the importance and the mandatory nature of measuring $\mathrm{BP}$ and assessing nutritional status during medical visits with adolescents. Considering the values obtained here, an action plan that includes guidance on healthy eating and that underscores the relevance of aerobic exercise as a preventive measure should be implemented.

The visit to request the MFC for school is many times the only chance of contact between individuals in this age group and the health system; for this reason, the MFC becomes an instance for education and empowerment in relation to healthy habits and practices in adolescence as a preparation for adult life.

To conclude, the rate of HTN in the studied adolescent population was $6.6 \%$ and was associated with the presence of obesity and LWC; no significant association was established with the other studied outcome measures.

\section{REFERENCES}

1. Organización Mundial de la Salud. Las 10 principales causas de defunción. [Accessed on: March 2019]. Available at: https: / / www.who.int/es / news-room/fact-sheets / detail/the-top-10-causes-of-death.

2. Argentina. Ministerio de Salud. Dirección Nacional de promoción de la salud y control de enfermedades no transmisibles. Mortalidad. [Accessed on: April 2019]. Available at: http:/ / www.msal.gob.ar/ent/index.php/ vigilancia/areas-de-vigilancia/mortalidad.

3. Assadi F. Prehypertension: a warning sign of future cardiovascular risk. Int J Prev Med. 2014; 5(Suppl 1):S4-9.

4. Yang Q, Zhong Y, Merritt R, Coqswell ME. Trends in High Blood Pressure among United States Adolescents across Body Weight Category between 1988 and 2012. J Pediatr. 2016; 169:166-73.e3.

5. Abraham CW, Blanco G, Coloma G, Cristaldi A, et al. ERICA. Estudio de los factores de riesgo cardiovascular en adolescentes. Rev Fed Arg Cardiol. 2013; 42(1):29-34.

6. Díaz A, Calandra L. Presión arterial elevada en niños y adolescentes escolarizados de Argentina en los últimos 25 años: revisión sistemática de estudios observacionales. Arch Argent Pediatr. 2017; 115(1):5-11.

7. Redwine K, Falkner B. Progression of Prehypertension to Hypertension in Adolescents. Curr Hypertens Rep. 2012; 14(6):619-25.

8. Comité Nacional de Nutrición, Sociedad Argentina de Pediatría. Guías de práctica clínica para la prevención, el diagnóstico y el tratamiento de la obesidad. Arch Argent Pediatr. 2011; 109(3):256-66.

9. Organización Mundial de la Salud. Recomendaciones mundiales sobre actividad física para la salud. 2010. [Accessed on: April 2019]. Available at: https: / / www.who. int/dietphysicalactivity/factsheet_recommendations/es/.

10. National High Blood Pressure Education Program Working Group on High Blood Pressure in Children and Adolescents. The Fourth Report on the Diagnosis, Evaluation, and Treatment of High Blood Pressure in Children and Adolescents. Pediatrics. 2004; 114(2 suppl, $4^{\text {th }}$ Report):555-76.

11. Grupo de Hipertensión, Sociedad Argentina de Pediatría. Consenso sobre factores de enfermedad cardiovascular en pediatría. Hipertensión arterial en el niño y el adolescente. Arch Argent Pediatr. 2005; 103(4):348-66.

12. Cossio-Bolaños $M$, Cossio-Bolaños W, Araya Menacho A, Gómez Campos R, et al. Estado nutricional y presión arterial de adolescentes escolares. Arch Argent Pediatr. 2014; 112(4):302-7.

13. Gotthelf S, Fonseca M. Hipertensión arterial y su asociación con variables antropométricas en adolescentes escolarizados de la ciudad de Salta (Argentina). Rev Fed Arg Cardiol. 2012; 41(2):96-102.

14. Zeberio N, Malpeli A, Apezteguia M, Carballo M, et al. El estado nutricional de niños escolares y su relación con la tensión arterial. Arch Argent Pediatr. 2013; 111(2):92-7.

15. Szer G, Kovalsky I, De Gregorio M. Prevalencia de sobrepeso, obesidad y su relación con hipertensión arterial y centralización del tejido adiposo en escolares. Arch Argent Pediatr. 2010; 108(6):492-8. 